\title{
Cross-Scale Analysis of Fire Regimes
}

\author{
Donald A. Falk, ${ }^{1,4, *}$ Carol Miller, ${ }^{2}$ Donald McKenzie, ${ }^{3}$ and Anne E. Black ${ }^{2}$
}

${ }^{1}$ Laboratory of Tree-Ring Research, University of Arizona, Tucson, Arizona 85721, USA; ${ }^{2}$ Aldo Leopold Wilderness Research Institute, US Forest Service, Rocky Mountain Research Station, Missoula, Montana 59801, USA; ${ }^{3}$ Pacific Wildland Fire Sciences Lab, US Forest Service, Washington, Seattle 98103, USA; ${ }^{4}$ School of Natural Resources, University of Arizona, Tucson, AZ 85721, USA

\begin{abstract}
Cross-scale spatial and temporal perspectives are important for studying contagious landscape disturbances such as fire, which are controlled by myriad processes operating at different scales. We examine fire regimes in forests of western North America, focusing on how observed patterns of fire frequency change across spatial scales. To quantify changes in fire frequency across spatial scale, we derive the event-area (EA) relationship and the analogous interval-area (IA) relationship using historical and simulated data from low- and highseverity fire regimes. The EA and IA provide multiscale descriptions of fire regimes, as opposed to standard metrics that may apply only at a single scale. Parameters and properties of scaling functions (intercept, slope, minimum value) are asso-
\end{abstract}

ciated statistically with properties of the fire regime, such as mean fire-free intervals and fire size distributions, but are not direct mathematical transformations of them because they also reflect mechanistic drivers of fire that are non-stationary in time and space. Patterns in fire-scaling relations can be used to identify how controls on fire regimes change across spatial and temporal scales. Future research that considers fire as a cross-scale process will be directly applicable to landscape-scale fire management.

Key words: landscape fire; fire regime; eventarea relationship; interval-area relationship; multiscale analysis; simulation models; neutral models; climate regime; SIMPPLLE.

\section{INTRODUCTION}

Ecosystem properties, whether continuous (for example, productivity and other fluxes) or discrete (for example, species richness), vary across spatial and temporal scales (Delcourt and Delcourt 1988; Morgan and others 1994; Millar and Woolfenden 1999). Understanding the relationship of scale dependence in ecosystem properties to their variability in space and time is one of the principal aims of ecological research (Levin 1992; Peterson and Parker 1998; Brown and West 2000; Peters and others 2007; Willig and others 2007).

Disturbances such as fire, storms, droughts, and insect outbreaks often occur in pulses or episodes, followed by ecosystem responses whose magni-

The authors contributed equally to this paper.

Received 25 August 2006; accepted 30 April 2007; published online 21 July 2007.

*Corresponding author; e-mail: dafalk@u.arizona.edu tudes generally reflect the intensity of disturbance (Pickett and White 1985; Lertzman and Fall 1998; Turner and others 2001; Suding and others 2003). Because the attributes of individual disturbance events are spatially and temporally variable, disturbance regimes are often characterized by aggregate properties such as frequency, duration, intensity, severity, seasonality or area affected per unit time (Table 1). In the case of wildfire, these aggregate properties are often reduced to single metrics, thereby simplifying much of the complexity of fire as an ecosystem process in two ways: first, focusing on averages eliminates potentially informative variability; second, focusing on a single scale may obscure ecologically important crossscale interactions (Peters and others 2004, 2007). For example, mean values of fire frequency, size, or severity may have little value in predicting ecological effects, which can exhibit non-linear or threshold behavior in response to variability among 


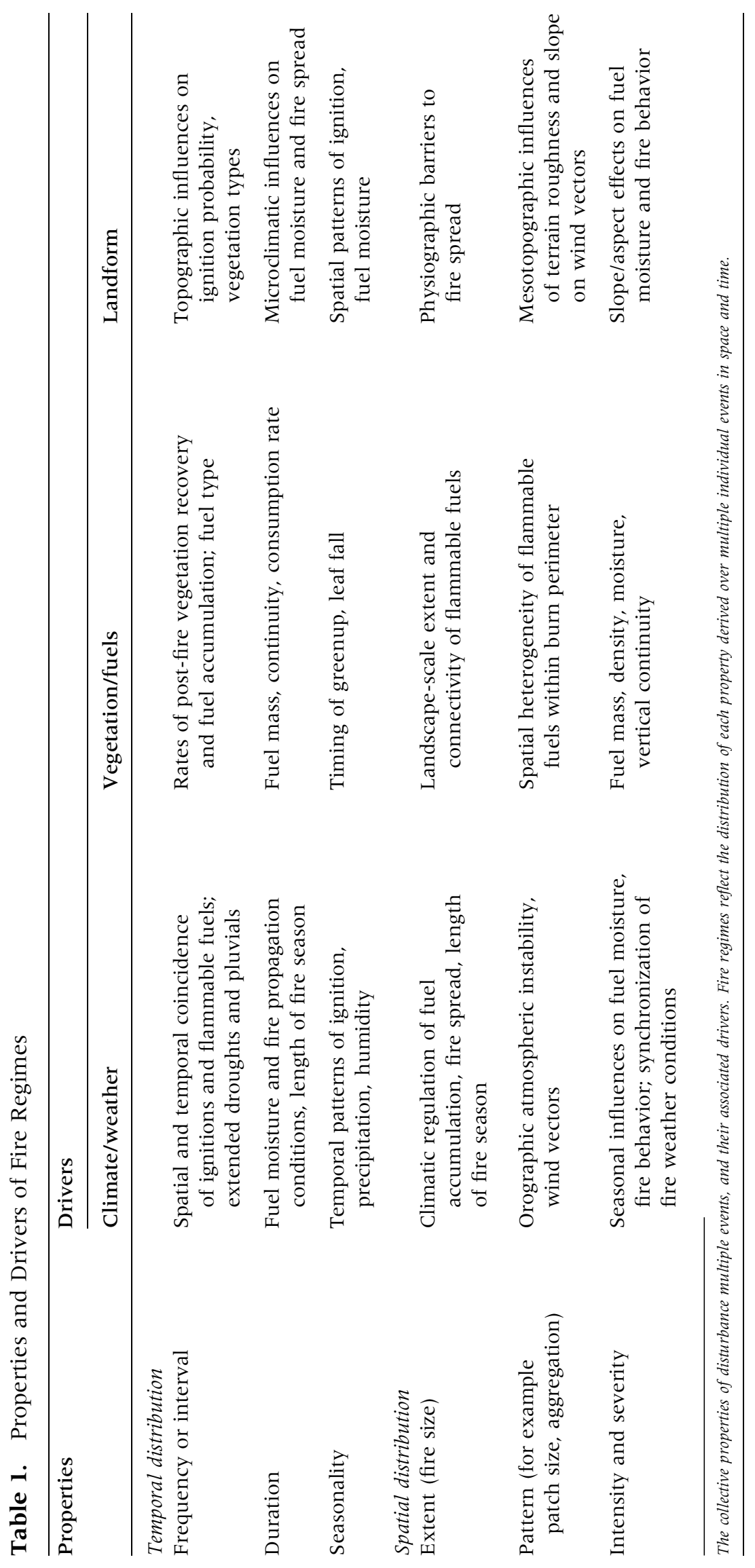




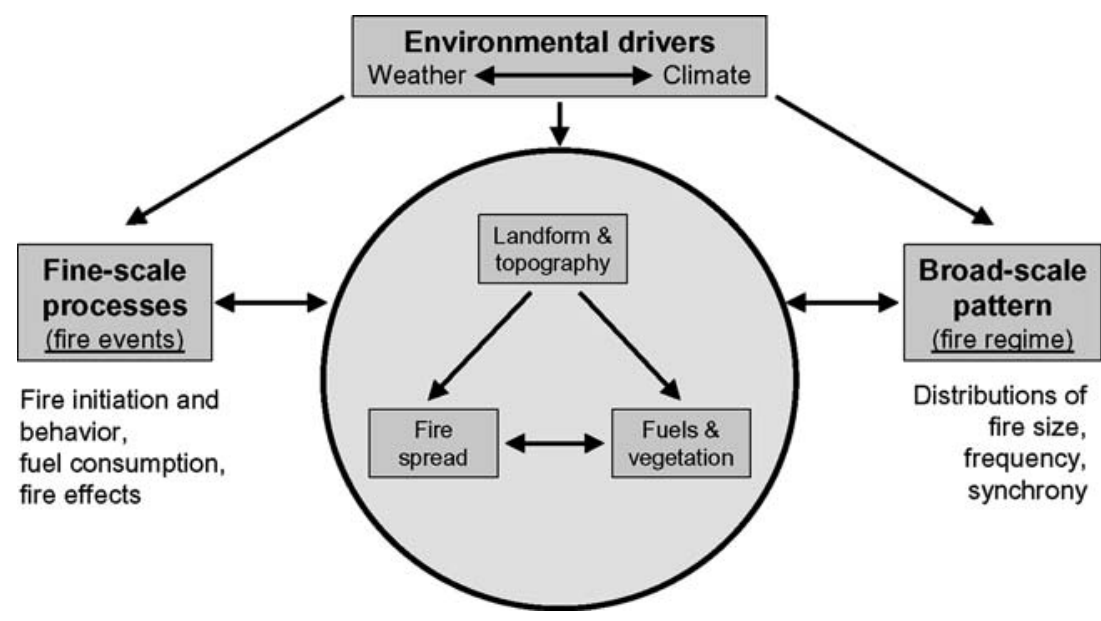

Figure 1. Cross-scale interactions of pattern and process in fire regimes. Environmental drivers of weather and climate, interacting with landform, set the overall template for individual fire events and fire regimes. Interactions between fire spread and vegetation determine the properties of fires at fine scales, while creating broad-scale landscape pattern. multiple events (Romme and others 1998; Peters and others 2004). Spatial heterogeneity in burn severity and patch size is a crucial component of both immediate fire effects and trajectories of ecosystem recovery (Turner and others 1997; Lertzman and others 1998; Kotliar and others 2003). Similarly, variability in fire-free intervals can alter mortality patterns and vegetation succession significantly (Keith and Bradstock 1994; Morrison and others 1995; Clark 1996).

The influences of governing mechanisms (climate, fuels, topography) and key properties of fire regimes (for example, individual fire behavior vs. fire-size distributions) vary across scales in specific ways (Simard 1991; Hessl and others 2004; Peters and others 2004) (Figure 1). For instance, over small spatial extents $\left(10^{-1}-10^{2} \mathrm{~m}^{2}\right)$ and time $\left(10^{-2}-10^{2} \mathrm{~h}\right)$ fire ignition and spread are dominated by fuel type, moisture, and continuity; air temperature, humidity, and windspeed; and microtopography (Rothermel 1983). Over larger extents $\left(10^{3}-10^{4} \mathrm{ha} ; 10^{2}-10^{4} \mathrm{~h}\right)$, different factors, such as stand-level vegetation, macrotopography, seasonal weather and synoptic climate, govern fire occurrence and behavior (Schroeder and others 1964; Nash and Johnson 1996; Westerling and Swetnam 2003; Schoennagel and others 2004; Mermoz and others 2005; Crimmins 2006). At bioregional scales $\left(>10^{5} \mathrm{ha}\right)$ and over longer time periods $\left(10^{1}-10^{3}\right.$ year), decadal to millennial variation in climate and the regional mosaic of vegetation types become important (Lynch and others 2003; Hessburg and others 2005). Observing fires at only a single scale of space and time inevitably presents an incomplete picture (Higuera 2006). Moreover, fire interacts with other ecosystem disturbance processes at multiple scales (Allen 2007).
Landscape fire is governed in part by stochastic processes; often its aggregate properties can be estimated but individual realizations appear random and are largely unpredictable (Lertzman and others 1998). For example, whereas individual fire sizes are difficult to estimate, many fire-size distributions display robust power-law behavior over several orders of magnitude (Malamud and others 2005). Both power-law behavior and deviations from such models permit inferences about mechanisms that control fire sizes (Reed and McKelvey 2002; Moritz and others 2005). Fire frequency and fire occurrence are similarly stochastic, in that aggregate statistics are more tractable for analysis than single events (fire starts) or fire-free intervals.

In this paper, we show how fire frequency scales in space, produces power-law behavior analogous to that shown by fire size distributions, and is also subject to mechanistic interpretations. We present an overview of observed variation in fire frequency at multiple spatial scales in several forested ecosystems across western North America. We then examine how properties of fire regimes and physical mechanisms influence these scaling patterns. We explore three questions:

1. How does fire frequency change with the spatial scale of observation, and is there evidence of general scaling functions?

2. How might aggregate properties of fire regimes, such as fire size distribution, influence the parameters of scaling functions?

3. How do physical mechanisms (climate, fuel dynamics, and topographic constraints) interact across scales to influence the fire scaling functions?

We ask these questions about diverse ecosystems using fire history data of different types (for 
example, point vs. area data) to isolate general scaling patterns and develop hypotheses about their drivers. We outline several viable research approaches to move the study of fire as a landscape and ecosystem process into an explicitly cross-scale framework, and to use this framework ultimately to inform ecosystem management at multiple scales.

\section{Theory and Observations of Scale- Dependent Behavior in Fire Regimes}

A scaling theory for fire regimes can be derived by extension from the biogeographic paradigm and the analytical framework of species-area theory. The familiar species-area relationship (SAR) is expressed formally as a power-law, $S=c A^{z}$ (where $S$ is species richness, $A$ is area, $c$ is a normalization constant, and $z$ is a dimensionless scaling exponent; $c$ and $z$ typically vary with taxon, ecosystem type, and landscape structure). Samples from larger areas capture more species, although generally at a declining rate (small areas are more species-rich per unit area than large areas), reflected in a range of scaling exponents generally $0.20 \leq z \leq 0.40$ (Rosenzweig 1995).

Scaling behavior of fire occurrence has been described using an analogous relationship referred to as the Event-Area (EA) relationship (Falk and Swetnam 2003, Falk 2004). If we substitute fire dates (years in which fire occurred) for species, the EA can be constructed by counting the number of fire dates $(F$, analogous to $S)$ captured in samples of increasing area. However, unlike the SAR, which is normally estimated for a single time period, the analogous analysis for fire occurrence must include a correction for temporal depth of the data record. For instance, a single tree may record multiple fire dates as fire-scarred tree-rings during its lifetime; similarly, the composite fire-scar record for a fire history plot may include multiple fires recorded by several trees over several hundred years (Fritts and Swetnam 1989).

To correct for the time dimension, the SAR is adapted by normalizing the length of time over which the number of fires are counted, using the metric of frequency $\left(f\right.$, number of fires time $\left.{ }^{-1}\right)$. Then the EA relationship becomes,

$$
f=d A^{y}
$$

where $A$ is area and $y$ is a dimensionless parameter analogous to $z$ (Falk 2004). Fire frequency is scaled by estimating its value at each $A_{i}=0 \ldots k$, where $A_{i}$ is the areal extent over which a composite fire record is obtained, and $A_{0}$ is the smallest measured spatial scale (Falk 2004; McKenzie and others 2006). The normalization parameter $d$ is derived from the fire frequency at the smallest measured spatial scale, $f_{0}$. Because the underlying model is a power equation, the log-transformed form of the EA

$$
\log f=\log d+y \log A
$$

is a useful linear model: $\log d$ is the intercept, and $y$ is the slope (the rate of change of frequency with sample area) of the log form of the EA. Fire-free intervals can be analyzed similarly. Let $\bar{I}=\frac{1}{n} \sum_{j=1}^{n} I_{j}$, the mean of $n$ fire intervals separating $n+1$ events. The interval-area (IA) relationship posits that $\bar{I}=f(y)$, for which a model is

$$
\bar{I}=I_{0} A^{-y} .
$$

The IA function is the mathematical inverse of the EA curve (the units of $\bar{I}$ are year fire ${ }^{-1}$ ). Like the log form of the EA, the log-transformed form of the IA can be used to separate the effects on the scaling function of $I_{0}$ and $y$ respectively.

EA and IA functions provide a way to describe how fire frequency varies with spatial scale of observation. If fires are consistently large and synchronous across the landscape, then increasing the sampling area will capture few new fire dates. In this case, the slope parameter will be small (close to 0 ) and the curve will appear as a relatively horizontal line in log-log space. Alternatively, if fires are consistently relatively small and patchy, new fire dates will be encountered with progressively larger sample areas, and a steeper EA or IA function will result. A full derivation of the EA/IA model is found in Falk (2004).

Scaling behavior of fire frequency has been observed informally in a variety of ecosystems. Arno and Petersen (1983) reported systematic relationships between sample area and estimates of mean fire interval $(\bar{I})$ for a study area in western Montana. Fire records for individual trees were aggregated into composite records for areas of approximately $0.5,4-6,20-40$, and 80-320 ha. Mean fire interval varied significantly with area of the composite; moreover, different vegetation types and topographic settings manifested different scaling slopes.

Scaling properties can also be derived from reanalysis of published data. For example, we reanalyzed fire intervals reported by Kilgore and Taylor (1979) for a 1,800 ha area of Sequoiadendron giganteum (giant sequoia)-mixed conifer forest in the Sierra Nevada. Fire records were compiled for the years 1700-1985 AD for composites of 

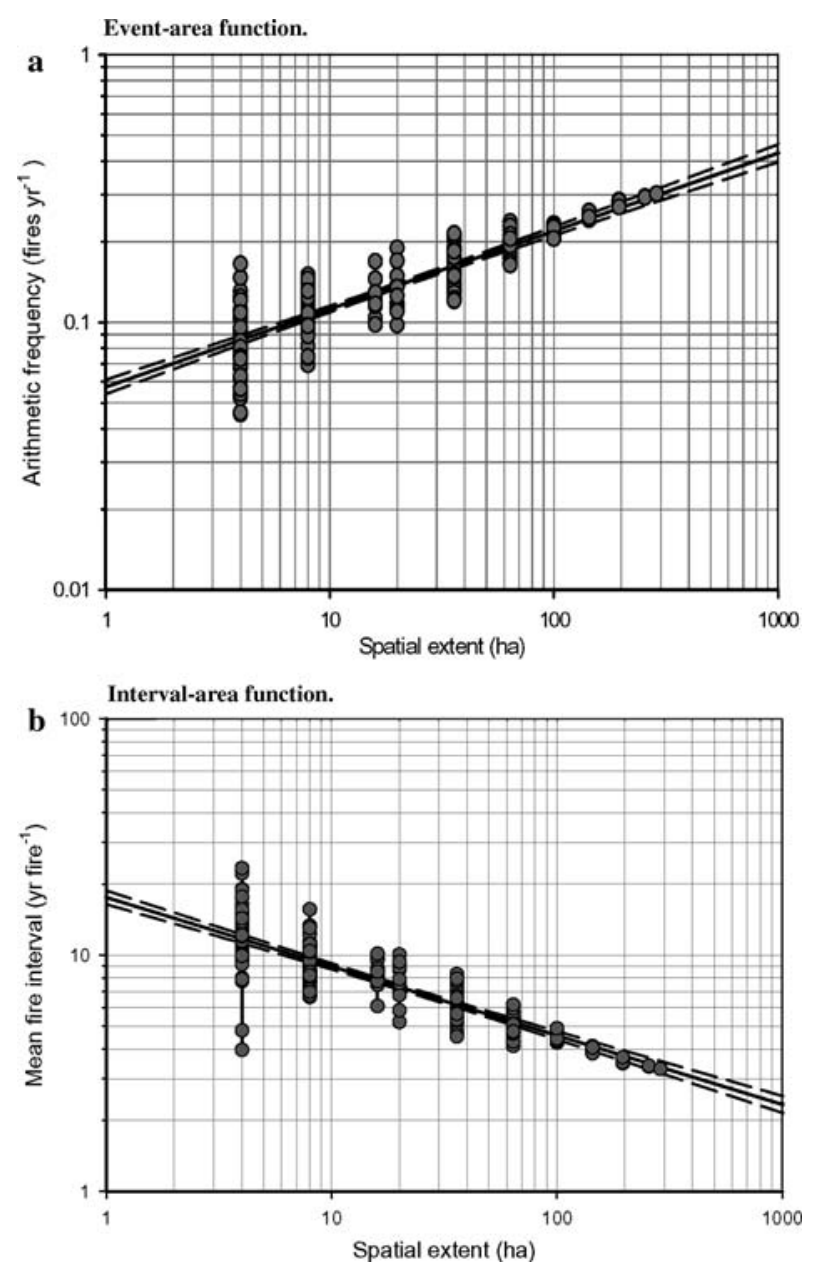

Figure 2. Event-area and interval-area functions for Monument Canyon Research Natural Area, New Mexico (Falk 2004). Fire frequency (A) and mean fire interval (B) are strongly scale-dependent on spatial extent $\left(0.78<r_{\text {adj }}^{2}<0.80, y=|0.29| \pm 0.01, P \leq 0.0001\right)$. Axes scaled logarithmically. Dashed lines are 95\% CI for fitted function.

individual trees $\left(10-50 \mathrm{~m}^{2}\right)$, clusters of trees (0.4-0.8 ha), sites (3.2-16.2 ha), and drainages (777-1,036 ha). Reanalysis indicates clear scale dependency of mean fire interval $(y=-0.19$, $\left.r^{2}=0.91\right)$.

Investigations that explicitly address scaling properties of fire regimes have yielded similar findings (Falk and Swetnam 2003; Moritz 2003; McKenzie and others 2006; Van Horne and Fulé 2006; Farris 2007). Falk (2004) used a gridded sampling design to investigate the scaling properties of an old-growth New Mexico Pinus ponderosa (ponderosa pine) forest. Fire frequency and fire intervals were calculated for composite fire records in moving windows of 4-280 ha. Fire frequency and mean fire interval were strongly scale depen- dent (Figure 2). Scaling slopes accounted for 76-81 percent of variation in fire intervals across multiple scales; scaling exponents were $0.27 \leq y \leq 0.30$.

Fire-scar records are intrinsically point data, but EA/IA relationships can also be generated using area data provided by fire atlases or fire-year maps. We compiled digitized fire perimeters from 18801996 AD for a 900,000 ha landscape comprising the SBW in northern Idaho and western Montana (Rollins and others 2001; Miller and Alaback 2003). Fire dates were then counted within randomly placed analysis windows of different sizes (400-144,000 ha) and EA functions were computed for three geographic subregions (Figure 3). The dependence of fire frequency on sample area was reflected in positive slope parameters of the EA for all three subregions $(y=0.43-0.53$; $0.97>r^{2}>0.99$; Table 2).

Scaling functions have been observed in simulated data. McKenzie and others (2006) created a "neutral" landscape of 200 fire-scarred trees on which low severity fires occurred at intervals drawn randomly from a negative exponential distribution. Mean fire-free intervals (Weibull Median Probability Interval) in this simulated landscape exhibit strong dependence on sample area $\left(0.89>r^{2}>0.95\right.$; Figure 4).

\section{What Properties of Fire Regimes CONTROL EvENT- AND INTERVAL-AREA SCALING?}

To interpret the differences in these scaling functions across ecosystems, we offer hypotheses for how fire frequency and size influence the minimum value, intercept, and slope of the EA/IA scaling model. For illustration purposes we use the inverse form, the interval-area relation (IA) in the 2-dimensional space of $(\log [x], \log [y])$ (Figure 5).

Overall fire frequency within the sample area determines the minimum value of the IA scaling function, $I_{\min }$. Because mean fire frequency for the study area truncates the line at this point, there is no meaningful interpretation for extents larger than $A_{\text {study }}$ area. Mean fire-free interval for the smallest measurable area, $A_{0}$ (point fire frequency) influences the expected value of the $y$-intercept $I_{0}$ (Figure $5 \mathrm{H}_{1}$ ).

The distribution of fire sizes influences the slope, $y$. Larger fires decrease $|y|$ whereas smaller fires increase this term (Figure $5 \mathrm{H}_{2}$ ); the slope would approach 0 as mean fire size approaches study area size. The slope may also be influenced by the variance in fire sizes. Recent simulations (not shown) 


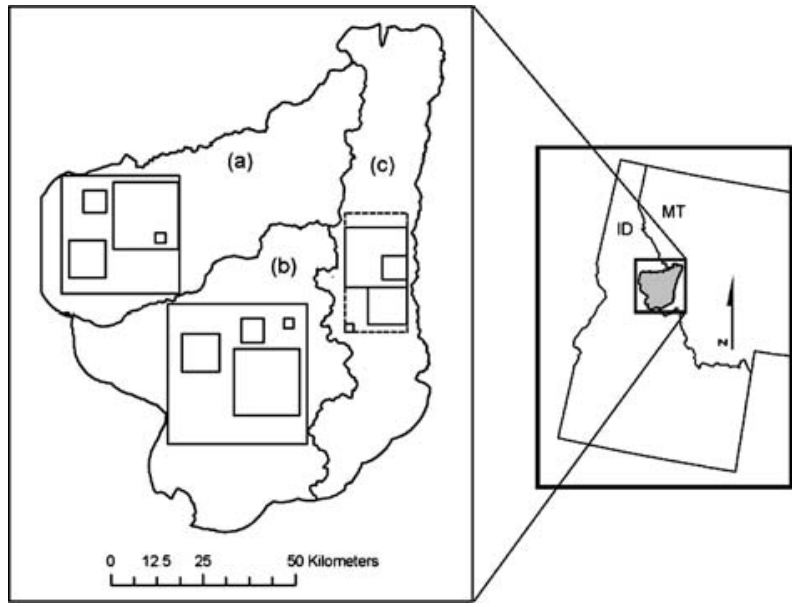

Figure 3. The $a$ Northwest, $b$ West Central, and $c$ Montana subregions of the Selway-Bitterroot Wilderness and the sizes of windows used for scaling analyses.

sensu McKenzie and others (2006), using either Gaussian or Gamma fire-size distributions, suggest that for a constant mean fire size, the slope of the IA becomes flatter as the variance increases. The slope also reflects the temporal synchrony of fires across the landscape. The effect of one large fire per year on the slope may be the same as many small fires per year, especially if these fires are widely distributed throughout the landscape. Therefore, when viewed across spatial extents much larger than the size of the largest fires, it may make more sense to speak of area-burned distributions in relation to the slope, rather than size distributions of individual fires.

To explore fire regime properties that may drive scaling functions, we used a spatial landscape dynamic model, SIMulating Pattern and Processes at Landscape scales (SIMPPLLE) (Chew and others 2004). SIMPPLLE simulates complex interactions between vegetation and disturbance (for example, insects and fire) in a contagious manner, using topography and conditions in adjacent 1 -ha cells to determine dynamics. Fire severity is determined by interactions of weather, fuel conditions, and topography, and a single fire may include a mix of fire severities. Using empirical ignition probabilities representative of an 18,090 ha watershed in the Bitterroot valley of western Montana (buffered by 1 $\mathrm{km}$ to account for fire spread into the study area), we simulated landscape dynamics for 100 years using two fire size distributions. In a "small-fire" simulation, all fires were less than 40 ha, whereas in a contrasting "large-fire" scenario (which also included areas of mixed and high-severity burn), 80\% of fires were larger than 405 ha, with the largest being 4,651 ha. To mimic the destruction of fire history records that can occur after moderate to high severity fires, we re-sampled the resulting fire census, eliminating records preceding all high severity fire and $40 \%$ (randomly selected) of the records preceding moderate severity fire. As expected, scaling slopes were flatter for the large-fire simulation than for the small-fire simulation $(y=-0.42$ and -0.47 respectively; (2006) (Figure 6).

\section{Physical Mechanisms and their INFLUENCE ON SCAling RELATIONSHIPS}

Different mechanisms regulating the distribution of fires in space and time dominate at different scales (Chang 1999; Peters and others 2004). Broad-scale interactions of climate, topography, and vegetation influence fire regimes at time scales of decades to centuries and across geographic regions to continental scales (Figure 7). Physiographic structures such as mountains modify the length of both the growing and fire season. At sub-annual and annual time scales, climate and fuels-and their interactions-affect fire behavior, with physical features such as slope and aspect modifying the influence of climate on fuel moistures and heat transfer processes. In the following discussion, we focus on climate, fuels, and landform as constraints affecting fire frequency and fire size, and thus the slope and intercept of the EA/IA.

\section{Climate}

Long-term climate and short-term weather act on the spatial and temporal distribution of fires directly through local effects on daily to weekly fuel moisture, ignition probability, and fire spread, and indirectly by mediating effects on vegetation and fuels. At time scales of minutes to days, wind, relative humidity, temperature, and precipitation affect ignition patterns, fuel moisture and fire behavior directly (Rothermel 1983; Johnson and Miyanishi 2001), whereas vegetation creates within-stand microclimatic conditions indirectly affecting diurnal fuel moistures (Countryman 1977; Pook and Gill 1993). At time scales of weeks to years, snowpack and synoptic seasonal weather patterns affect fuel moisture profiles directly, and rates of fuel production and decomposition indirectly (Miller and Urban 1999; Bachelet and others 2001; Beaty and Taylor 2001). Over decades and longer, regional and continental climatic gradients affect vegetation productivity and fuel accumulation rates (Lenihan and others 2003), and can serve 
Table 2. Scaling Model Parameters and Regression Results for Selway-Bitterroot Fire History

\begin{tabular}{lllll}
\hline & & Northwest & West central & Montana \\
\hline Entire period & 117 year & & & \\
$(1880-1996)$ & $d$ & 0.1352 & 0.0720 & 0.0734 \\
& $y$ & 0.4280 & 0.5119 & 0.5286 \\
Dry years (PDSI <0) & $r^{2}$ & 0.97 & 0.99 & 0.99 \\
& 53 year & & & 0.0421 \\
& $d$ & 0.2056 & 0.0491 & 0.5389 \\
Wet years (PDSI $>0)$ & $y$ & 0.3395 & 0.99 & $>0.99$ \\
& $r^{2}$ & 0.97 & 0.0008 & 0.0297 \\
& 48 year & & 0.0001 & $>0.8913$ \\
& $d$ & 1.1277 & & 0.94
\end{tabular}

See text and Figure 3 for model abbreviations and study area locations. Instrumental PDSI data are for the 101-year period of record 1895-1995 inclusive. Data from Miller and Alaback (2003).

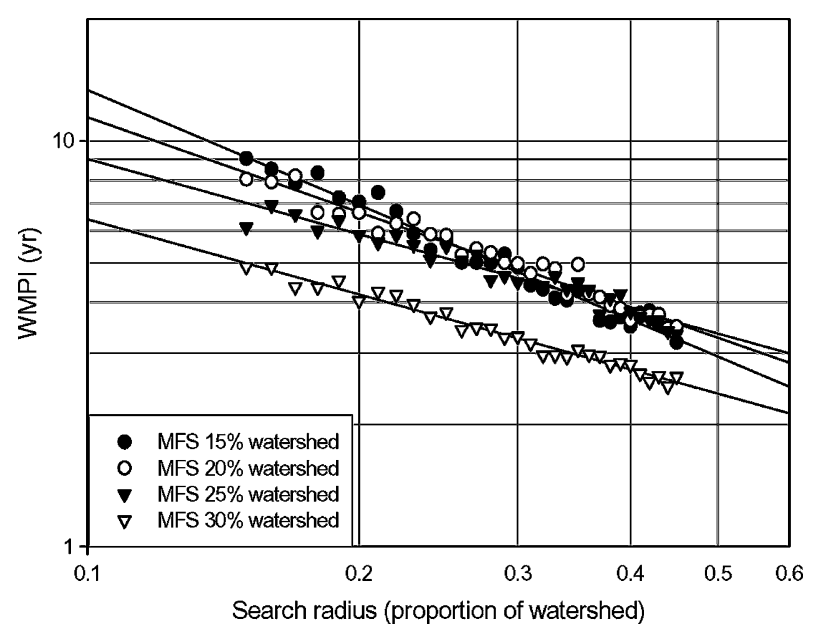

Figure 4. Interval-area scaling plots for simulated search areas. Mean values of Weibull Median Probability Interval (WMPI) from 20 replicates of composite fire records, compiled from search radii of $15-45 \%$ of the width of a simulated watershed. Log-log regression functions are fit to each of four mean fire sizes (15-30\% of watershed area). Strong scale dependence is indicated by regression fits $\left(0.89>r^{2}>0.95\right)$. Adapted from McKenzie and others 2006 .

as a dominant synchronizing agent (Heyerdahl and others 2002; Hallett and others 2003; Weisberg and Swanson 2003).

Climate and weather influence fire size distributions and frequency through influences on fuel continuity, ignition rates and season length, and fire behavior. Fire frequencies are higher during periods of extended drought; in lower productivity forest types, greater fire synchrony occurs after several years of high moisture during which biomass accumulates (Swetnam and Baisan 2003;
Brown and $\mathrm{Wu} 2005)$. Climate regimes that cause longer fire seasons lead to larger fires and more area burned (Wotton and Flannigan 1993; Hessl and others 2004).

Climate is non-stationary, and its control on the distributions of fires can be discontinuous. Anomalies or extreme weather events (for example, Santa Ana winds and multi-year drought) may be more important than mean conditions (Moritz 2003). Regional fire occurrence may also be influenced by phase transitions of the Pacific Decadal Oscillation (PDO) and Atlantic Multidecadal Oscillation (AMO), or during coincident phases of teleconnected climate cycles (Kitzberger and Veblen 2003; McCabe and others 2004; Hessburg and others 2005). These low-frequency climate signals may be manifested in non-stationary behavior of EA/IA scaling parameters (Falk 2004).

\section{Fuels}

Fuel conditions (for example, type, amount, moisture) influence fire size and frequency primarily through fire intensity and spatial continuity. Surface fuels affect the spread rate and intensity of surface fires (Rothermel 1983; Andrews and others 2003) while the amount and arrangement of ladder and canopy fuels affect the initiation and propagation of crown fires (Van Wagner 1977; Cruz and others 2006). Surface, ladder, and crown fuels vary at fine spatial scales $\left(10^{-1}-10^{2} \mathrm{~m}^{2}\right)$, depending on crown architecture, canopy gaps, and where branches and needles happen to land. At middle to large spatial scales $\left(10^{4}-10^{6} \mathrm{~m}^{2}\right)$, fuels vary with disturbance history and site productivity. Similarly, the temporal dynamics of fuel loads depend on the 


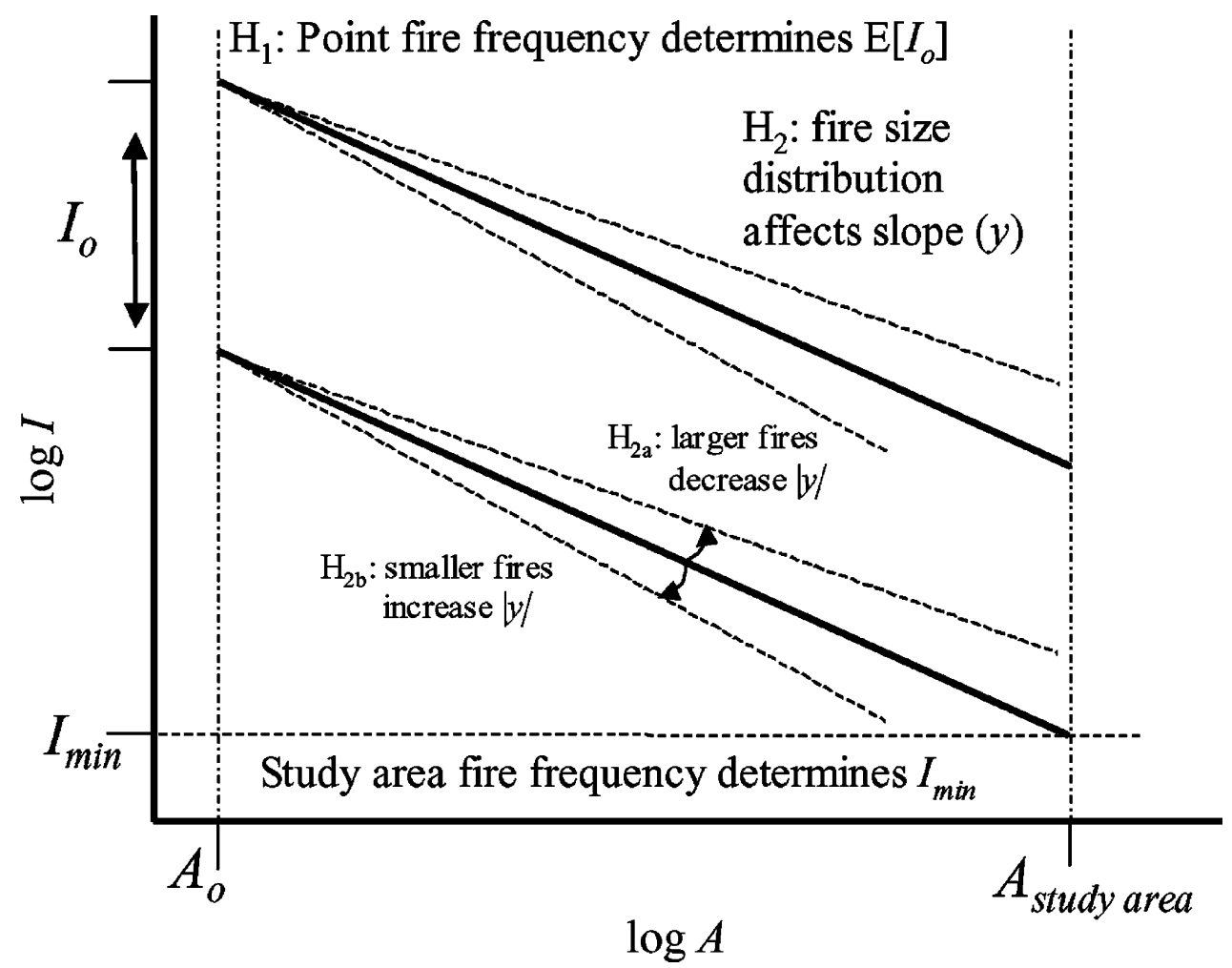

Figure 5. Controls on the behavior of the IA function, plotted logarithmically. Fire regime properties (annual area burned, mean and variance of fire size distribution, and fire frequency) control the intercept $\left(I_{0}\right)$, slope $(y)$, and minimum value $\left(I_{\min }\right)$ of the scaling function.

type of fuel (for example, live or dead biomass), particle size, and production and decomposition rates.

The spatio-temporal dynamics of fuel accumulation influence both fire frequency and size distributions. Because there is often a lag time for accumulation of fuels before fire can reburn an area, fuel dynamics on time scales of months to decades can limit fire frequency in fuel-limited ecosystems (Agee and others 1978; Stohlgren 1988; Baker 2003). Invasions of fire-dependent plant species can also alter fire frequencies (D`Antonio and Vitousek 1992). Spatial connectivity of fuels influences the distribution of fire sizes via the effect on fire spread (Turner and Romme 1994; Miller and Urban 2000). Furthermore, temporal dynamics of fuel condition and abundance can synchronize fire occurrence, as can climate cycles that contribute to herbaceous growth (Swetnam and Betancourt 1990; Veblen and others 2000) or regionalscale insect outbreaks (Fleming and others 2002).

\section{Landform}

Landform influences fire regimes through its effects on ignition frequency and spatial distribution, fire

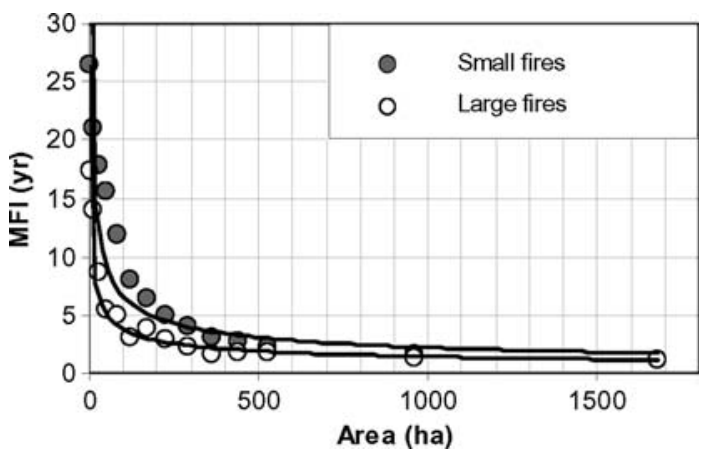

Figure 6. Interval-area plot for SIMPPLE simulations. A power model explains the majority of variation in MFI for simulated fire history reconstruction in both largeand small-fire scenarios. Small fires (filled circles): $d=57.1$ year fire ${ }^{-1}, y=-0.47, r^{2}=0.86$. Large fires (open circles): $d=26.3$ year fire ${ }^{-1}, y=-0.42, r^{2}=0.94$. Axes scaled logarithmically.

behavior, and fire spread across landscapes. At broad spatial scales $\left(10^{4}-10^{6} \mathrm{ha}\right)$, orographic gradients generate persistent local climate variation, inducing variation in vegetation and fuel productivity (Gavin and others 2003). For example, slope and aspect modify processes of heat transfer (via 


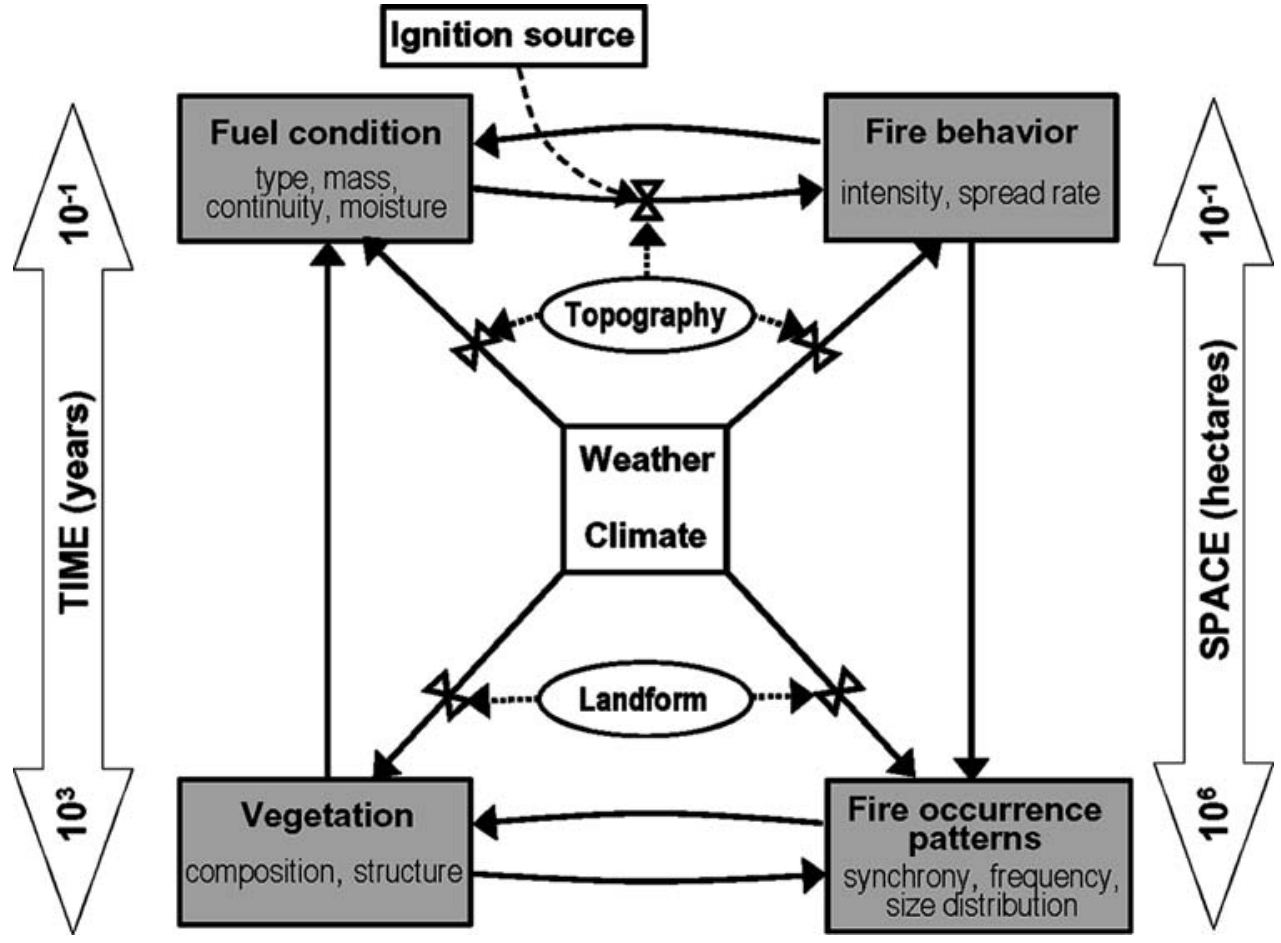

Figure 7. Conceptual model linking factors that govern fire regimes across space and time. At short-term and stand scales, primary interactions are among fuel condition, weather, and fire behavior if there is a source of ignition. At longer term and regional scales, primary interactions are among vegetation, climate, and patterns of fire occurrence. Topography and landform modify the influence of weather and climate, the spatial distribution of ignition, and processes of heat transfer in combustion (for example, slope effects).

solar radiation) and precipitation and temperature (via adiabatic lapse rates with elevation), both well established direct influences on fuel production and moisture (Daly and others 1994; Dubayah and Rich 1995; Taylor and Skinner 2003). At finer scales $\left(10^{-1}-10^{2} \mathrm{ha}\right)$, topography creates microclimatic variability affecting plant water balance, fuel moisture, and soil development. Other influences include orographic effects on lightning storm tracks and spatial patterns of ignitions (van Wagtendonk 1994).

Fire spread is governed partly by slope, aspect, and terrain roughness. Certain landforms can present physical barriers to fire spread that can bound fires, thus affecting fire size and area burned (Frost 1998; Kellogg 2004). Other landform configurations promote fire spread and can govern fire occurrence and area burned (Chang 1999; Gavin and others 2003).

\section{Influence of Variability on Scaling Relationships}

Spatial and temporal variability in climate, fuels, and landform is reflected in the EA/IA slope, intercept, and minimum value. For example, interactions of climate and landform affect the rate at which vegetation and fuel loads can recover after fire. Fuel recovery times influence point frequency of fire and the intercept of the EA/IA curve. Climate anomalies that magnify extremes of fire weather or extend fire seasons will lead to larger fires and more variability in the distribution of fire sizes, which will flatten the slope of the EA/IA. By contrast, periods of relatively homogeneous climate may create more consistent fire occurrence patterns; the resulting reduced variability in the distribution of fire sizes will steepen the EA/IA slope. Highly dissected topography can present multiple effective barriers to fire spread, limiting the large end of the fire size distribution, increasing the number of asynchronous events across the landscape, and steepening the scaling slope.

Variability in climate, fuels, and landform may also be reflected in the departures from the EA/IA model. Climate variability that drives highly variable fire-free intervals shows up as scatter along the EA/IA model. Landscape heterogeneity in post-fire recovery rates of fuels, and refugia from fire (Camp and others 1997; McKenzie and others 2006) will also be seen as departures from the model. 

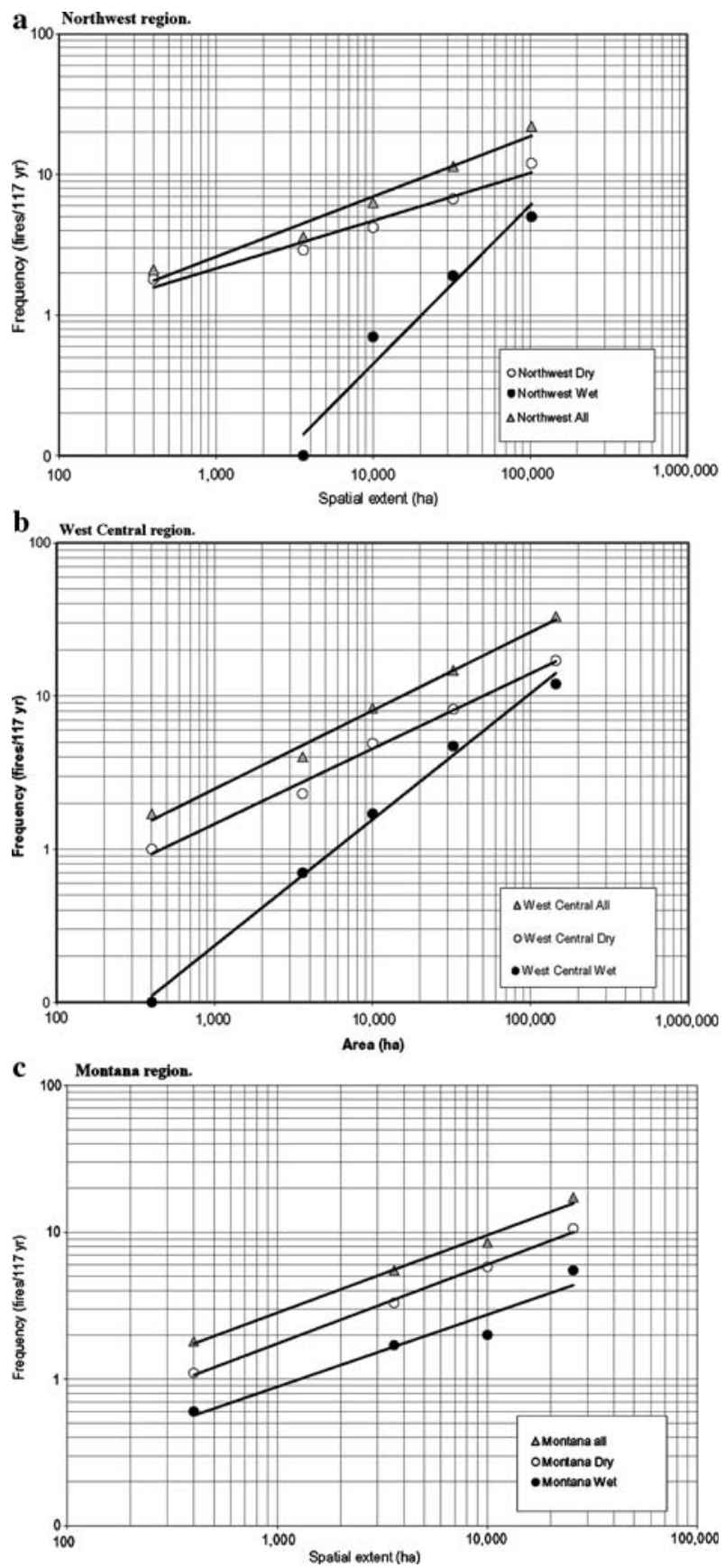

Figure 8. Log-log event-area plots for three climatic regions of the Selway-Bitterroot Wilderness, Idaho-Montana, USA (see Figure 3). A Northwest region. B West Central region. C Montana region. Dry years (PDSI < 0 , open circles), wet years (PDSI >0, filled circles), all years combined (grey triangles). Axes scaled logarithmically. Data from Miller and Alaback (2003).

\section{Case study: Selway-Bitterroot Wilderness, Idaho/Montana, USA}

To explore how parameters of the EA/IA reflect these physical mechanisms, we used the fire atlas data described earlier for three subregions of the Selway-Bitterroot Wilderness (Miller and Alaback 2003). We generated separate EA functions for dry (mean annual Palmer Drought Severity Index [PDSI $]<0.00$ ) and wet (PDSI >0.00) years. A gridded PDSI reconstruction (Cook and others 1999) was used to assign each year between 1895 and 1995 as dry or wet.

For two of the subregions, scaling slopes were lower when only dry years were used to construct the EA (mean annual Palmer Drought Severity Index $[\mathrm{PDSI}]<0.00)$ compared to when only wet years were used (PDSI > 0.00; Figure 8, Table 2). These differences suggest that the slope of the EA/ IA may be a useful indicator of the effects of interannual climate variability on fire frequency and size distributions.

We found interesting differences among the three geographic subregions, suggesting that the slope reflects differences in landform and climate. In dry years, the slope of the EA was lowest in the Northwest subregion, which is characterized by a warm-wet climate, compared to the eastern subregion in Montana, which is more consistently cool and dry. By contrast, in wet years when fires were less extensive, the slopes exhibited the opposite pattern, with the Northwest subregion having the highest slope. The difference in slopes between dryversus wet-years was most apparent in the Northwest subregion, where the topography is much more homogeneous than in the Montana subregion, which is characterized by steep, narrow drainages.

\section{Research Directions and Management ApPliCATIONS}

In its most basic application, the EA/IA model provides a framework for describing fire regimes at multiple spatial scales. It also may contain implicit information about other fire regime statistics, and may prove useful for understanding underlying mechanisms that influence fire regimes. In this concluding section we (1) outline steps for validating the EA/IA framework as a description of fire regimes, (2) suggest how the EA/IA might be used to explore governing mechanisms, and (3) discuss applications to ecosystem management.

\section{Validating the framework}

We have illustrated EA and IA functions for a handful of ecosystem types, across a range of landscape sizes, and derived these functions using point (for example, fire-scarred tree ring) and area 
(for example, fire perimeter) data. Here we propose additional empirical and simulation studies to validate the EA/IA framework.

First, the framework should be tested in additional ecosystem types such as boreal and mixed conifer forests, shrublands, and grasslands (Baker 1989; Moritz 2003). Many existing fire history studies already have the requisite geospatial information to estimate parameters of EA/IA models (Taylor and Skinner 1998; Heyerdahl and others 2001). With such datasets becoming increasingly available (NOAA 2007), meta-analysis of scaling functions calculated from available fire history studies from various parts of North America is possible and would help clarify the differences in scaling relationships among ecosystem types.

A major uncertainty with any fire history is missing data. Tree-rings provide an imperfect record of low severity fires, and these records may be destroyed entirely by high severity events. Fire perimeter maps are similarly prone to errors, often missing small and low severity fires (Rollins and others 2001; Farris 2007). To quantify the sensitivity of the EA/IA to these different sources of missing data, empirical or simulated fire history data can be "filtered" according to the proportion of trees or sites recorded fire in each year (Van Horne and Fulé 2006; Farris 2007). Mean fire interval derived using data for all fires will be most strongly scale dependent, because even small and asynchronous fires are included. Progressively stronger filters reduce the slope of the scaling function, because only relatively widespread fires exceed the filter threshold. Simulation models also offer a means of separating the respective effects of sample extent and grain, area, and the temporal pattern of fire occurrence on scaling behavior of fire regimes (Li 2002).

Additional research is needed to clarify the relationship of the EA/IA to other fire regime descriptors, for which we propose the use of both neutral landscape models and more complex vegetation simulators. "Neutral models" in community and landscape ecology generalize the concept of a null hypothesis to an array of patterns and processes that capture relevant details of a system, while eliminating constraints or mechanisms of interest (Gardner and O`Neill 1991; Gotelli and Graves 1996). For example, McKenzie and others (2006) simulated "neutral" historical patterns of lowseverity fire to produce an IA model with no forcing functions (Figure 4), that is, a scaling relation that is not shaped by ecosystem processes. By running controlled experiments in this type of simulation environment (for example, Keane and
Finney 2003), we can test inferences about fire size distributions (per se and relative to study area size), spatiotemporal synchrony and fire frequencies from the parameters of the EA/IA. More complex vegetation simulators offer the option to test and compare forcing functions on real landscapes under a variety of biologic and climatologic conditions, providing a more realistic 'laboratory' for exploratory and explanatory research.

\section{Exploring Mechanisms}

The EA/IA relationship connects patterns of fire occurrence to climate and fuel conditions at multiple scales, providing a framework for investigating physical mechanisms that drive fire regimes. Here we suggest some ways to explore these physical mechanisms.

Climate exhibits variability at multiple temporal scales (Gedalof and others 2002; McCabe and others 2004), and fire regimes respond to climate variation at decadal and longer periods as well as "fire year" weather (Heyerdahl and others 2002; Hessl and others 2004; Brown and others 2005). Long fire history data sets can be partitioned by quasi-periodic climate phases (for example, decadal interactions of ENSO, PDO, and AMO) or by longer climate "regimes" (Hessburg and others 2005; Higuera 2006) before constructing an EA or IA function. Differences among climate phases in scaling slopes or intercepts would suggest multiyear climatic controls on fire regimes. Methods to determine where to partition these data include intervention analysis (Box and Jenkins 1976), singular spectrum analysis (Ghil and others 2002), and multivariate techniques such as the combined classification and ordination of climate series (Hessburg and others 2005). Fire data might also be partitioned into nonconsecutive years (for example, Figure 8) according to departures from a longterm climatic mean, such as deviation from mean PDSI.

Comparisons of landscapes with similar climate could distinguish the relative influence of climatic versus landform controls at different spatial scales. For example, fire history datasets can be partitioned by landform, bioclimatic zones, or topographic variance analysis (Kellogg 2004; Taylor and Skinner 2003). By examining climate regimes or anomalies for different landscapes, we can ask about the interactions between climate and landform in producing variation in scaling parameters, thereby refining our understanding of the multiple drivers of fire regimes (Hessburg and others 2005). A particularly intriguing possibility is that if we can 
identify robust relationships between underlying forcing mechanisms (such as climatic variability and topographic pattern) and aggregate multi-scale properties of fire regimes such as the EA/IA relationship, we might extrapolate scaling relationships to areas or periods for which spatially explicit fire data are unavailable.

Because fire depends ultimately on biological production ("fuel"), there is a direct connection between the drivers of fire size and frequency, and mechanisms governing ecosystem productivity (Olson 1963). Scaling in ecological systems parallels energetic relationships (Brown and West 2000; Enquist and Niklas 2001; Enquist and others 2003), and it has been suggested that the fire-fuel feedback can be a self-organizing force (Holling 1992; Malamud and others 2005). This is an important area of research that could clarify linkages among mechanistic processes, scaling relationships, and underlying ecosystem energetics (Moritz and others 2005). Comparison of EA/IA curves for ecosystems with similar productivity and fuel accumulation rates but different degrees of exposure to extreme weather could distinguish the relative influence between fuels and climatic controls on fire regimes.

We suggest examining the statistical model used to fit the EA/IA scaling function and conducting a formalized study of drivers of patterns of regression residuals. Departures from the predicted powerlaw relationship may help to reveal controls (such as topography) or forcing functions (such as energetic constraints) at particular scales (Ricotta and others 2001). For instance, patterns in residuals may help determine the spatial scale at which climate variation and landform replace fire spread and fuel dynamics as the dominant constraint on large fire years.

\section{Management Applications}

The EA/IA framework has several potential applications to ecosystem management. For example, a nonzero slope parameter indicates plainly to a land manager that measures of fire frequency are areadependent, and that fire return interval cannot be described by a single number independent of spatial scale. Different scaling slopes derived from different subregions of a landscape (for example, Table 2) suggest that fire or vegetation management strategies may need to be tailored to each subregion.

If the studies we outlined earlier validate the EA/ IA framework, it might be used to detect the effect of recent management or land use on scaling of fire regimes. For example, in their investigations with the SBW fire atlas data, Miller and Alaback (2003) derived EA functions for different time periods during the twentieth century. They found that scaling slopes for two of the three subregions in the SBW appear to have changed, becoming steeper in recent years. Although the SBW has an active "wildland fire use" program that allows many natural ignited fires to burn, the apparent changes in scaling slopes suggest that these landscapes may have been re-scaled by suppression of fires that would have otherwise become large. Suggestively, scaling slopes for the Montana subregion-which contains numerous topographic barriers to fire spread-did not change through time.

If we are successful in clarifying the relationship between the EA/IA and aggregate properties of the fire regime such as fire size distributions, a manager might better anticipate consequences of different fire management strategies. For example, broadening the prescription window for the wildland fire use strategy could mean larger fires, and a manager might use the EA/IA to forecast how a shift in fire sizes might affect the fire frequency experienced at the stand level.

\section{ConClusion}

Complex interactions of fuels, topography, and climate influence the behavior and effects of individual fires. The relative importance of each factor is also dependent on the spatial and temporal scale of observation. Fire frequency, fire intervals, fire rotation, and area-burned distributions are aggregate properties that emerge from analysis of multiple events in space and time. These emergent properties in turn affect the cross-scale patterns that can be observed in event- and interval-area scaling relationships. Because the mechanisms that drive fire occurrence and extent have inter-annual and quasi-periodic variability, we expect scaling relationships and associated fire size or area-burned distributions to be non-stationary over time, possibly reflecting distinct climate regimes and anomalies. Scaling studies also offer potential links to ecosystem energetics, reflecting the combined influences of climate, topography, and vegetation on rates of biomass production. Cross-scale analyses can greatly expand the frame of reference provided by studies currently being undertaken at specific scales of space and time.

\section{ACKNOWLEDGEMENTS}

This paper originated from a special session on landscape fire regimes organized by Miller and 
McKenzie at the 2004 meeting of the International Association for Landscape Ecology. We thank Monica Turner, Bai-lin Li, and Debra Peters for encouraging us to develop this manuscript. We especially acknowledge the contributions of the other participants in that symposium: Paul Hessburg, Phil Higuera, Todd Kipfer, and Max Moritz. Calvin Farris, Rudy King, and Thomas Swetnam provided helpful comments on earlier drafts.

\section{REFERENCES}

Agee JK, Wakimoto RH, Biswell HH. 1978. Fire and fuel dynamics of Sierra Nevada conifers. For Ecol Manage 1:255265.

Allen CD. 2007. Interactions across spatial scales among forest dieback, fire, and erosion in northern New Mexico landscapes. Ecosystems (This issue).

Andrews PL, Bevins CD, Seli RC. 2003. BehavePlus fire modeling system, version 2.0: User's Guide. Gen. Tech. Rep. RMRSGTR-106WWW. Ogden, UT: Department of Agriculture, Forest Service, Rocky Mountain Research Station.

Arno SF, Peterson TD. 1983. Variation in estimates of fire return intervals: a closer look at fire history on the Bitterroot National Forest. General Technical Report GTR INT-301, USDA Forest Service. Ogden, UT: Intermountain Research Station.

Bachelet D, Neilson RP, Lenihan JM, Drapek RJ. 2001. Climate change effects on vegetation distribution and carbon budget in the United States. Ecosystems 4:164-85.

Baker WL. 1989. Effects of scale and spatial heterogeneity on fire-interval distributions. Can J For Res 19:700-06.

Baker WL. 2003. Fires and climate in forested landscapes of the U.S. Rocky Mountains. In: Veblen TT, Baker W, Montenegro G, Swetnam TW, Eds. Fire and Climatic change in temperate ecosystems of the Western America. New York: Springer. pp $116-53$.

Beaty RM, Taylor AH. 2001. Spatial and temporal variation of fire regimes in a mixed conifer forest landscape, Southern Cascades, California, USA. J Biogeogr 28:955-66.

Box GEP, Jenkins GM. 1976. Time series analysis: forecasting and control. San Francisco: Holden-Day.

Brown JH, West GB, Eds. 2000. Scaling in biology. New York: Oxford University Press.

Brown KJ, Clark JS, Grimm EC, Donovan JJ, Mueller PG, Hansen BCS, Stefanova I. 2005. Fire cycles in North American interior grasslands and their relation to prairie drought. Proc Natl Acad Sci 102:8865-70.

Brown PM, Wu R. 2005. Climate and disturbance forcing of tree recruitment in a southwestern ponderosa pine landscape. Ecology 86:3030-38.

Camp A, Oliver C, Hessberg P, Everett R. 1997. Predicting latesuccessional fire refugia pre-dating European settlement in the Wenatchee Mountains. For Ecol Manage 95:63-77.

Chang C-R. 1999. Understanding fire regimes. Ph.D. dissertation. Duke University, Durham.

Chew JD, Stalling C, Moeller K. 2004. Integrating knowledge for simulating vegetation change at landscape scales. Western Journal of Applied Forestry 19:102-8.

Clark JS. 1996. Testing disturbance theory with long-term data: alternative life-history solutions to the distribution of events. Am Nat 148:976-96.
Cook ER, Meko DM, and others 1999. "Drought reconstructions for the continental United States." J Clim 12:11451162 .

Countryman CM. 1977. Radiation effects on moisture variation in ponderosa pine litter. Forest Service Research Paper PSW126, USDA Forest Service, Pacific Southwest Forest and Range Experiment Station, Berkeley.

Crimmins MA. 2006. Synoptic climatology of extreme fireweather conditions across the southwest United States. Int J Climatol 26:1001-16.

Cruz MG, Butler BW, Alexander ME, Forthofer JM, Wakimoto RH. 2006. Predicting the ignition of crown fuels above a spreading surface fire. Part I: Model idealization. Int J Wildland Fire 15:47-60.

Daly C, Neilson RP, Phillips DL. 1994. A statistical-topographical model for mapping climatological precipitation over mountainous terrain. J Appl Climatol 33:140-58.

D’Antonio CM, Vitousek PM. 1992. Biological invasions by exotic grasses, the grass/fire cycle, and global change. Annu Rev Ecol Syst 23:63-87.

Delcourt HR, Delcourt PA. 1988. Quaternary landscape ecology: relevant scales in space and time. Landsc Ecol 2:23-44.

Dubayah R, Rich PM. 1995. Topographic solar radiation models for GIS. Int J Geogr Info Syst 9:405-19.

Enquist BJ, Economo EP, Huxman TE, Allen AP, Ignace DD, Gillooly JF. 2003. Scaling metabolism from organisms to ecosystems. Nature 423:639-42.

Enquist BJ, Niklas KJ. 2001. Invariant scaling relations across tree-dominated communities. Nature 410:655-60.

Falk DA. 2004. Scaling rules for fire regimes. Ph.D. Dissertation. University of Arizona, Tucson.

Falk DA, Swetnam TW. 2003. Scaling rules and probability models for surface fire regimes in Ponderosa pine forests. In: Omi PN, Joyce LA, Eds. Fire, fuel treatments, and ecological restoration. US Forest Service, Rocky Mountain Research Station, Ft. Collins. pp 301-17.

Farris CA. 2007. Comparison of multiple methods for inferring fire history in a Sky Island mountain range. Ph.D. Dissertation. University of Arizona, Tucson.

Fleming RA, Candau J-N, McAlpine RS. 2002. Landscape-scale analysis of interactions between insect defoliation and forest fire in central Canada. Clim Change 55:251-72.

Fritts HC, Swetnam TW. 1989. Dendroecology: a tool for evaluating variations in past and present forest management. Adv Ecol Res 19:111-89.

Frost CC. 1998. Presettlement fire frequency regimes of the United States: a first approximation. In: Pruden TL, Brennan LA, Eds. Fire in ecosystem management: shifting the paradigm from suppression to prescription. Tall Timbers Research Station, Tallahassee, FL, Tall Timbers Fire Ecology Conference Proceedings. pp 70-81.

Gardner RH, O`Neill RV. 1991. Neutral models for landscape analysis. In: Turner MG, Gardner RH, Eds. Quantitative methods in landscape ecology. New York: Springer. Chap 11.

Gavin DG, Brubaker LB, Lertzman KP. 2003. Holocene fire history of a coastal temperate rain forest based on soil radiocarbon dates. Ecology 84:184-201.

Gedalof Z., Mantua NJ, Peterson DL. 2002. A multi-century perspective of variability in the Pacific Decadal oscillation: new insights from tree rings and coral. Geophys Res Lett 29:2204 . 
Ghil M, Allen MR, Dettinger MD, Ide K, Kondrashov D, Mann ME, Robertson AW, Saunders A, Tian Y, Varadi F, Yiou P. 2002. Advanced spectral methods for climatic time series. Rev Geophys 40:1-41DOI 10.1029/2001RG000092.

Gotelli NJ, Graves GR. 1996. Null models in ecology. New York: Smithsonian Books.

Hallett DJ, Lepofsky DS, Mathewes RW, Lertzman KP. 2003. 11,000 years of fire history and climate change in the mountain hemlock rain forests of southwestern British Columbia based on sedimentary charcoal. Can J For Res 31:292-12.

Hessburg PF, Kuhlman EE, Swetnam TW. 2005. Examining the recent climate through the lens of ecology: inferences from temporal pattern analysis. Ecol Appl 15:440-57.

Hessl AE, McKenzie D, Schellhaas R. 2004. Drought and Pacific Decadal Oscillation linked to fire occurrence in the inland Pacific Northwest. Ecol Appl 14:425-42.

Heyerdahl EK, Brubaker LB, Agee JK. 2001. Spatial controls of historical fire regimes: a multiscale example from the Interior West, USA. Ecology 82:660-78.

Heyerdahl EK, Brubaker LB, Agee JK. 2002. Annual and decadal climate forcing of historical fire regimes in the interior Pacific Northwest, USA. Holocene 12:597-604.

Higuera PE. 2006. Late glacial and Holocene fire history in the southcentral Brooks Range, Alaska: direct and indirect impacts of climatic change on fire regimes. Ph.D. Dissertation. University of Washington, Seattle.

Holling CS. 1992. Cross-scale morphology, geometry, and dynamics of ecosystems. Ecol Monogr 62:447-502.

Johnson EA, Miyanishi K, Eds. 2001. Forest fires: behavior and ecological effects. San Diego: Academic Press.

Keane RE, Finney MA. 2003. The simulation of landscape fire, climate, and ecosystem dynamics. In: Veblen TT, Baker WL, Montenegro G, Swetnam TW, Eds. Fire and climatic change in temperate ecosystems of the Western Americas. New York: Springer. pp 32-68.

Keith DA, Bradstock RA. 1994. Fire and competition in Australian heath: a conceptual model and field investigations. J Veg Sci 5:347-54.

Kellogg LKB. 2004. Quantifying spatial structures associated with low-severity fire regimes in the eastern Cascade Mountains of Washington State, USA. M.S. Thesis. University of Washington, Seattle.

Kilgore BM, Taylor D. 1979. Fire history of a sequoia-mixed conifer forest. Ecology 60:129-42.

Kitzberger T, Veblen TT. 2003. Influences of climate on fire in Northern Patagonia, Argentina. In: Veblen TT, Baker WL, Montenegro G, Swetnam TW, Eds. Fire and climatic change in temperate ecosystems of the Western Americas. New York: Springer. pp 296-321.

Kotliar NB, Haire SL, Key CH. 2003. Lessons from the fires of 2000: Post-fire heterogeneity in Ponderosa pine forests. In: Omi PN, Joyce LA, Eds. Fire, fuel treatments, and ecological restoration. US Forest Service, Rocky Mountain Research Station, Ft. Collins. pp 277-79.

Lenihan JM, Drapek R, Bachelet D, Neilson RP. 2003. Climate change effects on vegetation distribution, carbon and fire in California. Ecol Appl 13:1667-81.

Lertzman KP, Fall J. 1998. From forest stands to landscapes: Spatial scales and the roles of disturbance. In: Peterson DL, Parker VT, Eds. Ecological scale: theory and applications. New York: Columbia University Press. pp 339-67.
Lertzman KP, Fall J, Dorner B. 1998. Three kinds of heterogeneity in fire regimes: at the crossroads of fire history and landscape ecology. Northwest Sci 72:4-23.

Levin SA. 1992. The problem of pattern and scale in ecology. Ecology 73:1943-67.

Li C. 2002. Estimation of fire frequency and fire cycle: a computational perspective. Ecol Modell 154:103-20.

Lynch JA, Clark JS, Bigelow NH, Edwards ME, Finney BP. 2003. Geographic and temporal variations in fire history in boreal ecosystems of Alaska. J Geophys Res 108:1-17.

Malamud BD, Millington JDA, Perry GLW. 2005. Characterizing wildfire regimes in the United States. Proc Natl Acad Sci USA 102:4694-99.

McCabe GJ, Palecki MA, Betancourt JL. 2004. Pacific and Atlantic Ocean influences on multidecadal drought frequency in the United States. Proc Natl Acad Sci USA 101:4136-41.

McKenzie D, Hessl AE, Kellogg LKB. 2006. Using neutral models to identify constraints on low-severity fire regimes. Landsc Ecol 21:139-52.

Mermoz M, Kitzberger T, Veblen TT. 2005. Landscape influences on occurrence and spread of wildfires in Patagonian forests and shrubland. Ecology 86:2705-15.

Millar CI, Woolfenden WB. 1999. The role of climate change in interpreting historical variability. Ecol Appl 9:1207-16.

Miller C, Alaback P. 2003. Landscape scale interactions between fire regimes and ecosystems. Agreement 99-35101-7828, Aldo Leopold Wilderness Institute. Final Report to the National Research Initiative Competitive Grants Program (Ecosystem Science), Missoula.

Miller C, Urban DL. 1999. Forest pattern, fire, and climate change in the Sierra Nevada. Ecosystems 2:76-87.

Miller C, Urban DL. 2000. Connectivity of forest fuels and surface fire regimes. Landsc Ecol 15:145-54.

Morgan P, Aplet GH, Haufler JB, Humphries HC, Moore MM, Wilson WD. 1994. Historical range of variability: a useful tool for evaluating ecosystem change. J Sus For 2:87-111.

Moritz MA. 2003. Spatiotemporal analysis of controls of shrubland fire regimes: age dependency and fire hazard. Ecology 84:351-61.

Moritz MA, Morais ME, Summerell LA, Carlson JM, Doyle J. 2005. Wildfires, complexity, and highly optimized tolerance. Proc Natl Acad Sci USA 102:17912-917.

Morrison DA, Carey GJ, Pengelly SM, Ross DG, Mullins BJ, Thomas CR, Anderson TS. 1995. Effects of fire frequency on plant species composition of sandstone communities in the Sydney region: interfire interval and time-since-fire. Aust $\mathrm{J}$ Ecol 20:239-47.

Nash CH, Johnson EA. 1996. Synoptic climatology of lightningcaused forest fires in subalpine and boreal forests. Can J For Res 26:1859-74.

NOAA. 2007. IMPD: The International Multiproxy Paleofire Database (http://www.ncdc.noaa.gov/paleo/impd/).

Olson JS. 1963. Energy storage and the balance of producers and decomposers in ecological systems. Ecology 44:322-31.

Peters DPC, Bestelmeyer BT, Turner MG. 2007. Cross-scale interactions and changing pattern-process relationships: consequences for ecosystem dynamics. Ecosystems (This issue).

Peters DPC, Roger Pielke S A, Bestelmeyer BT, Allen CD, Munson-McGee S, Havstad KM. 2004. Cross scale interactions, nonlinearities, and forecasting catastrophic events. Proc Natl Acad Sci 101:15130-5. 
Peterson DL, Parker VT. 1998. Ecological scale: theory and applications. New York: Columbia University Press.

Pickett ST A., White PS, Eds. 1985. The ecology of natural disturbance and patch dynamics. New York: Academic.

Pook EW, Gill AM. 1993. Variation of live and dead fine fuel moisture in Pinus radiata plantations of the Australian-CapitalTerritory. Int J Wildland Fire 3:155-68.

Reed WJ, McKelvey KS. 2002. Power-law behavior and parametric models for the size-distribution of forest fires. Ecol Modell 150:239-54.

Ricotta C, Arianoutsou M, Díaz-Delgado R, Duguy B, Lloret F, Maroudi E, Mazzoleni S, Moreno JM, Rambal S, Vallejo R, Vázquez A. 2001. Self-organized criticality of wildfires ecologically revisited. Ecol Modell 141:307-11.

Rollins MG, Swetnam TW, Morgan P. 2001. Evaluating a century of fire patterns in two Rocky Mountain wilderness areas using digital fire atlases. Can J For Res 31:2107-23.

Romme WH, Everham EH, Frelich LE, Moritz MA, Sparks RE. 1998. Are large, infrequent disturbances qualitatively different from small, frequent disturbances?. Ecosystems 1:524-34.

Rosenzweig ML. 1995. Species diversity in space and time. Cambridge: Cambridge University Press.

Rothermel RC. 1983. How to predict the spread and intensity of wildfires. USDA Forest Service General Technical Report INTGTR-143, Intermountain Research Station, Missoula.

Schoennagel T, Veblen TT, Romme WH. 2004. The interaction of fire, fuels, and climate across Rocky Mountain forests. BioScience 54:661-76.

Schroeder MJ, Glovinsky M, Hendricks VH. 1964. Synoptic weather types associated with critical fire weather. USDA Forest Service, Berkeley.

Simard AJ. 1991. Fire severity, changing scales, and how things hang together. Int J Wildland Fire 1:23-34.

Stohlgren TJ. 1988. Litter dynamics in two Sierran mixed conifer forests, I. Litter fall and decomposition rates. Can J For Res 18:1127-35.

Suding KN, Gross KL, Houseman GR. 2003. Alternative states and positive feedbacks in restoration ecology. Trends Ecol Evol 193:46-53.

Swetnam TW, Baisan CH. 2003. Tree-ring reconstructions of fire and climate history in the Sierra Nevada and southwestern United States. In: Veblen TT, Baker W, Montenegro G, Swetnam TW, Eds. Fire and climatic change in temperate ccosystems of the Western Americas. New York: Springer. pp 158-95.
Swetnam TW, Betancourt JL. 1990. Fire-Southern Oscillation relations in the southwestern United States. Science 249:1017-20.

Taylor AH, Skinner CN. 1998. Fire history and landscape dynamics in a late-successional reserve, Klamath Mountains, California, USA. For Ecol Manage 111:285-301.

Taylor AH, Skinner CN. 2003. Spatial patterns and controls on historical fire regimes and forest structure in the Klamath Mountains. Ecol Appl 13:704-19.

Turner M, Romme. 1994. Landscape dynamics in crown fire ecosystems. Landsc Ecol 9:59-77.

Turner MG, Collins SL, Lugo AE, Magnuson JJ, Rupp TS, Swanson FJ. 2001. Disturbance dynamics and ecological response: the contribution of long-term ecological research. Bioscience 53:46-56.

Turner MG, Romme WH, Gardner RH, Hargrove WW. 1997. Effects of patch size and fire pattern on succession in Yellowstone National Park. Ecol Monogr 67:411-33.

Van Horne ML, Fulé. 2006. Comparing methods of reconstructing fire history using fire scars in a southwestern United States ponderosa pine forest. Can J For Res 36:855-67.

Van Wagner CE. 1977. Conditions for the start and spread of crown fires. Can J For Res 7:23-34.

van Wagtendonk JW 1994. Spatial patterns of lightning strikes and fires in Yosemite National Park. In: Proceedings of the 12th Conference on Fire and Forest Meteorology. Society of American Foresters, Bethesda, Jekyll Island.

Veblen TT, Kitzberger T, Donnegan J. 2000. Climatic and human influences on fire regimes in ponderosa pine forests in the Colorado Front Range. Ecol Appl 10:1178-95.

Weisberg PJ, Swanson FJ. 2003. Regional synchroneity in fire regimes of western Oregon and Washington, USA. For Ecol Manage 172:17-28.

Westerling AL, Swetnam TW. 2003. Interannual to decadal drought and wildfire in the Western US. EOS 84:545-60.

Willig M, Bloch C, Brokaw N, Zimmerman C, Thompson J. 2007. Cross-scale responses of biodiversity to hurricane and anthropogenic disturbance in a tropical forest. Ecosystems (This issue).

Wotton BM, Flannigan MD. 1993. Length of the fire season in a changing climate. For Chron 69:187-92. 